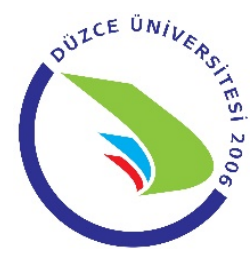

ORIJINAL MAKALE / ORIGINAL ARTICLE

Düzce Üniversitesi Sağlık Bilimleri Enstitüsü Dergisi / DÜ Sağlık Bil Enst Derg

Journal of Duzce University Health Sciences Institute / J DU Health Sci Inst

ISSN: 2146-443X sbedergi@duzce.edu.tr 2019; 9(2): 71-75

doi: https://dx.doi.org/10.33631/duzcesbed.503205

\title{
Ebelik Öğrencilerinin Problem Çözme Becerileri ile Öz Etkililik Yeterlik Düzeyleri Arasındaki İlişki
}

\author{
Keziban AMANAK ${ }^{1}{ }^{1}$, İlayda DEMIRKOL ${ }^{1}{ }^{1}$, Zeliha KURU ${ }^{1}$
}

ÖZ

Amaç: Araştırma ebelik öğrencilerinin problem çözme becerileri ile öz etkililik yeterlik düzeyleri arasındaki ilişkinin incelenmesi amacıyla yapılmıştır.

Gereç ve Yöntemler: Analitik ve kesitsel tipteki bu araştırma, Adnan Menderes Üniversitesi Sağlık Bilimleri Fakültesi Ebelik Bölümü’nde 2018-2019 eğitim öğretim yılı güz döneminde 310 ebelik öğrencisi ile yürütülmüştür. Verilerin toplanmasında; araştırmacılar tarafından oluşturulan Demografik Bilgi Formu, Problem Çözme Envanteri ve Öz Etkililik-Yeterlik Ölçeği kullanılmıştır. Verilerin analizi SPSS 18.0 paket programı ile yapılmıştır. Veriler Tek Yönlü Varyans Analizi (post-hoc Scheffe testi) ve Pearson Korelasyon testi ile değerlendirilmiştir.

Bulgular: Çalışmaya katılan öğrencilerin yaş ortalaması $21.13 \pm 2.56$ 'dır. Öğrencilerin öğrenim gördüğü sınıf seviyesi yükseldikçe problem çözme envanteri puan ortalamalarının azaldığı belirlenmiştir $(\mathrm{p}=0.029)$. Öğrencilerin sınıflara göre öz etkililik yeterlik toplam puan ortalamalarının birbirine oldukça yakın olduğu ancak bu farkın önemli olmadığı görülmüştür. Araştırmada öğrencilerin problem çözme becerileri ile öz etkililik yeterlik düzeyleri arasında negatif yönde orta şiddette anlamlı ilişki saptanmıştır $(\mathrm{p}<0.001)$.

Sonuç: Öğrencilerin problem çözme becerileri ile öz etkililik yeterlik düzeyleri arasında negatif yönde ilişki olduğu ve sınıflara göre problem çözme becerileri arasında fark saptanırken, öz etkililik yeterlik düzeyleri açısından fark bulunmamıştır. Bu sonuçlara istinaden farklı örneklem gruplarında ebelik öğrencilerinde problem çözme becerileri ile öz etkililik yeterlik düzeylerinin karşılaştırıldığı farklı çalışmaların yapılması, ebelik öğrencilerinin eğitim müfredatına problem çözme becerilerinin geliştirilmesine katkı sağlayacak seçmeli derslerin eklenmesi önerilebilir.

Anahtar Kelimeler: Ebelik; öz etkililik; problem çözme.

\section{The Relationship between Problem Solving Skills and Self Efficacy Proficiency Levels of Midwifery Students}

\begin{abstract}
Aim: The aim of this study was to investigate the relationship between self efficacy proficiency levels and problem solving skills of midwifery students.

Material and Methods: This analytical and cross-sectional study was conducted with 310 midwifery students during the fall semester of 2018-2019 academic year at Adnan Menderes University, Faculty of Health Sciences, Midwifery Department. In the collection of data; Demographic Information Form, Problem Solving Inventory and Self Efficacy Scale were used. Data were analyzed using SPSS 18.0 software. The data were evaluated by One-way Analysis of Variance (post-hoc Scheffe test) and Pearson's Correlation tests.

Results: The mean age of the students was $21.13 \pm 2.56$. It was determined that the mean score of the students in the problem solving inventory decreased as the grade level students were studying $(p=0.029)$. It was observed that the mean scores of self efficacy proficiency scores of the students were quite close to each other, but this difference was not significant. In the study, a significant negative correlation was found between the students' problem solving skills and self efficacy proficiency $(\mathrm{p}<0.001)$.
\end{abstract}

Conclusion: There was a negative correlation between problem solving skills and self efficacy proficiency levels of the

1 Adnan Menderes Üniversitesi, Sağlık Bilimleri Fakültesi, Ebelik Bölümü, Aydın, Türkiye

Sorumlu Yazar / Corresponding Author: Keziban AMANAK, e-mail: keziban.amanak@adu.edu.tr

Geliş Tarihi / Received: 28.12.2018, Kabul Tarihi / Accepted: 04.04.2019 
students, and there was no difference in self-efficacy proficiency levels. Based on these results, it can be suggested that different studies should be conducted to compare the problem solving skills of the midwifery students and self efficacy competencies in different sample groups, and to add elective courses that will contribute to the development of problem solving skills in the midwifery education curriculum.

Keywords: Midwifery; self efficacy; problem solving.

\section{GIRIŞ}

Ebelik eğitimi sonunda gerekli nitelikleri kazanmış ve yasal olarak lisanslı olan kişilere "ebe" denilmektedir (1). Ebelerin nitelikleri arasında iyi bir eğitim görmenin yanı sıra eleştirel düşünme becerisi ve problem çözme becerisi de yer almaktadır. Problem çözme becerisi, kişiyi çözüme götürecek bilgilerin kazanılması ve kullanıma hazır olacak şekilde birleştirilerek, bir sorunun çözümünü uygulayabilme düzeyidir. Problem çözme, bilişsel becerilerin yanı sıra duygusal ve davranışsal özellikleri de içeren oldukça karmaşık bir süreç olup, bireyin psikolojik uyumu, sosyal-duygusal yeterlik düzeyi, kendine güveni, iletişim becerilerinin etkililiği ve karar verme biçimleri, öz etkililik-yeterlik kavramı ile yakından ilişkilidir. Ebe ve ebelik öğrencilerinin yapacakları bakımları planlarken kullandıkları ebelik süreci, problem çözme yönteminin sistematik bir biçimde kullanılması olup, gerekli olan ebelik girişimlerinin planlanması, uygulanması ve sonucun değerlendirilmesi aşamalarından oluşan sistemli bir yaklaşımdır (2).

Bireyin belli bir eylemi başarıyla yapma veya problemleri çözmede öz etkililik yeterlik (ÖEY) düzeylerinin etkili olduğu düşünülmektedir. Öz etkililik yeterlik bireyin yaşamıyla ilgili olaylar üzerinde etkili olabilmesi, belli bir performansı göstermesi için gerekli etkinlikleri organize etmesi ve başarılı sonuç alabilme kapasitesine ilişkin kendi inancı olarak tanımlanmaktadır $(3,4)$. İnsanların sahip oldukları öz etkililik yeterlik inançları onların nasıl hissedeceklerini, düşüneceklerini, davranacaklarını ve kendilerini nasıl motive edeceklerini belirler. Belirli alanda ÖEY algısı yüksek olan bireylerin, kendilerini yetersiz olarak algilayanlardan daha farklı düşündükleri, hissettikleri ve davrandıkları belirtilmektedir (4). Ayrıca öz etkililik yeterlik düzeyinin, bireyin bir sorun ile karşılaştığında sorunu çözmek için ne kadar çaba harcayacağı konusunda etkili olduğu (5) ve öz etkililik yeterlik düzeyi yüksek olan kişilerin problem çözümünde daha başarılı oldukları bildirilmektedir (6). Britner (7) ile Bray ve arkadaşlarının (8) çalışmalarında öz etkililik düzeyi yüksek olan öğrencilerin akademik performanslarının da daha yüksek olduğu belirtilmektedir. Ebelik lisans eğitiminin hedefine bakıldığında; öğrenciye bilişsel, duyuşsal ve psikomotor boyutta temel mesleki bilgi, beceri ve tutumları kazandırmaktır. Bu hedeflere ulaşmak için öğrencilerin problem çözme becerileri ile öz etkililik yeterlik düzeylerinin yüksek tutulması gerekmektedir. Dolayısıyla öğrencilerin problem çözme becerilerinin ve öz etkililik yeterlik düzeylerinin belirlenmesi, öğretim sürecinde başarıyı artırmak için alınması gereken önlemlere ilişkin önemli bilgiler sağlayacak ve öğrenmeyi kolaylaştıracak stratejilerin geliştirilmesine yol gösterecektir. Tüm bu bilgilere dayalı olarak bu çalışma, ebelik öğrencilerinin öz etkililik yeterlik düzeyleri ve problem çözme becerileri arasındaki ilişkiyi belirlemek amacıyla yapılmıştır.

Araştırma soruları aşağıda sıralanmıştır;

(1) Ebelik öğrencilerinin problem çözme becerileri nasildir?

(2) Ebelik öğrencilerinin öz etkililik yeterlik düzeyleri nasıldır?

(3) Ebelik öğrencilerinin problem çözme becerileri ile öz etkililik yeterlik düzeyleri arasında ilişki var mıdır?

(4) Ebelik öğrencilerinin problem çözme becerileri ile öz etkililik yeterlik düzeyleri arasında sınıflara göre farklılık var midir?

\section{GEREÇ VE YÖNTEMLER}

Analitik ve kesitsel tipteki bu araştırma, Adnan Menderes Üniversitesi Sağlı Bilimleri Fakültesi Ebelik Bölümü'nde Kasım-Aralık 2018 tarihleri arasında yürütülmüştür.

Araştırmanın evrenini Ebelik Bölümünde öğrenim gören 386 öğrenci oluşturmuştur. Araştırmada örneklem seçimine gidilmemiş, tüm evrene ulaşılmaya çalışılmıştır. Araştırmada hastalık, okula devamsızlık, kayıt dondurma vb. nedenlerle 38 öğrenciye ulaşılamaması, 23 öğrencinin anket formlarını yanlış ya da eksik doldurması, 15 öğrencinin araştırmaya katılmak istememesi gibi nedenlerle 76 öğrenci araştırma kapsamına alınamamıştır. Verilerin toplanmasında; araştırmacılar tarafından oluşturulan Demografik Bilgi Formu (8 soru), öğrencilerin problem çözme becerilerinin belirlenmesi için Problem Çözme Envanteri (PÇE), öz etkililik yeterlik düzeyinin belirlenmesi için Öz Etkililik-Yeterlik Ölçeği (ÖEYÖ) kullanılmıştır. Araştırmanın veri formları öğrencilerin öz bildirimlerine dayalı olarak toplanmıştır. Demografik bilgi formu: Yaş, sınıf, gelir durumu, şu an yaşanılan yer, en uzun süre yaşanılan yer, aile tipi, kardeş sayısı, bölüme isteyerek gelme durumunu içeren 8 sorudan oluşmaktadır. Form araştırmacılar tarafindan literatür taranarak geliştirilmiştir $(2,3,9,10)$.

Problem çözme envanteri (PÇE): Bireyin problem çözme becerisi konusunda kendi algılayışını ölçen envanter Heppner ve Peterson (11) tarafından geliştirilmiştir. PÇE, 35 madde ve üç faktörden oluşmaktadır. Bunlardan birincisi problem çözme güveni (11 madde), ikincisi problemden kaçınma/yaklaşma (16 madde), üçüncüsü kontroldür (15 madde). PÇE bu üç faktörün özetidir. Ölçeğin orijinalinin Cronbach alfa tutarlılık katsayısı 0.90 , alt ölçekler için elde edilen katsayılar ise, 0.72 ile 0.85 arasında bulunmuştur. Ölçeğin alt ölçeklerinin test tekrar test güvenirlik katsayıları, $r=0.83$ ile $r=0.89$ arasında değişmektedir (12). Ergen ve yetişkinlere uygulanabilen 1-6 arası puanlanan likert tipi bir ölçektir. Ölçeğin puanlamasında 9, 22 ve 29 numaralı maddeler puanlama dışı tutulur. $1,2,3,4,11,13,14,15,17,21$, $25,26,30$ ve 34 numaralı maddeler ters olarak puanlanır. Ölçeğin Türkçe geçerlik ve güvenirliği Şahin ve ark. (13) tarafından yapılmıştır. Ölçeğin Cronbach alfa tutarlılık katsayısı 0.88 olarak bulunmuştur. Yapılan faktör analizi sonucunda ölçekte; aceleci yaklaşım $(13,14,15,17,21$, 25, 26, 30, 32. maddeler), düşünen yaklaşım (18, 20, 31, 33, 35. maddeler), kaçıngan yaklaşım (1, 2, 3, 4. maddeler), değerlendirici yaklaşım $(6,7,8$. maddeler), kendine güvenli yaklaşım $(5,23,24,27,28,34$. maddeler), planlı yaklaşım $(10,12,16,19$. maddeler $)$ 
olmak üzere altı faktör bulunmuştur. $\mathrm{Bu}$ çalışmada PÇE'nin toplam puanı kullanılmıştır. Ölçekten alınabilecek en düşük puan 32, en yüksek puan 192'dir. Ölçeğin değerlendirilmesinde kesme noktası bulunmamaktadır. Problem çözme envanterinden elde edilen puanın düşük olması problem çözme becerisinin yüksek olduğunu, yüksek olması ise problem çözme becerisinin zayıf olduğunu gösterir $(2,14)$. Bu çalışmada problem çözme envanterinin güvenirlik katsayısı 0.87 olarak bulunmuştur.

Öz etkililik-yeterlik ölçeği (ÖEYÖ): Sherer ve ark. (15) tarafından davranışsal değişimleri değerlendirmek üzere geliştirilen bir öz değerlendirme ölçeğidir. Ölçek 23 maddeden oluşmaktadır. Beşli Likert tipi olan ölçekte her bir madde; beni hiç tanımlamıyor-1, beni biraz tanımlıyor-2, kararsızım-3, beni iyi tanımlıyor-4, beni çok iyi tanımlıyor-5 şeklinde işaretlenmektedir. Her madde için verilen puan esas alınmaktadır. Ölçeğin 2, 4, 5, 6, 7, $10,11,12,14,16,17,18,20,22$. maddeleri ters yönde puanlanmaktadır. Ölçekten en az 23 puan, en fazla 115 puan alınabilmektedir. Ölçekten alınan toplam puanın yüksek olması, bireyin öz etkililik yeterlik algısının iyi düzeyde olduğunu göstermektedir. Türkçe formunun geçerlik güvenirliği Gözüm ve Aksayan tarafından (16) yapılmıştır. Ölçeğin tüm ifadelerinin dahil edildiği Cronbach alfa iç tutarlılık katsayısı 0.81, test-tekrar test güvenirliği 0.92 olarak bulunmuştur (16). Bu çalışmada öz etkililik-yeterlik ölçeğinin güvenirlik katsayısı 0.82 olarak bulunmuştur.

Araştırmanın uygulanabilmesi için Adnan Menderes Üniversitesi Sağlık Bilimleri Fakültesi Dekanlığından izin alınmıştır. Araştırma protokolü Adnan Menderes Üniversitesi Sağlı Bilimleri Fakültesi Klinik Araştırmalar Danışma Komisyonu Etik Kurulu tarafından uygun bulunmuştur (No: 2018/57). Öğrencilere çalışmanın amacı, anketi ve ölçekleri doldurma süresi, çalışmaya katılmanın gönüllülük esasına dayandığı, katılımlarını herhangi bir noktada sonlandırabilecekleri, verdikleri bilgilerin araştırma dışında kullanılmayacağı, anketlere isim yazmanın gerekli olmadı̆̆ gibi açıklamalar yapılıp, varsa soruları yanıtlandıktan sonra çalışmaya katılımları konusunda sözlü ve yazılı onamları alınmıştır.

\section{İstatistiksel Analiz}

Verilerin analizinde SPSS 18.0 paket programı kullanılmıştır. Verilerin normal dağılıma uygun olup olmadıklarını değerlendirmek için Kolmogorov-Smirnov ve Shapiro-Wilk testleri kullanılmıştır. Grup varyanslarının homojenliği Levene testi ile kontrol edilmiştir. Sınıflara göre öğrencilerin problem çözme becerileri ve öz etkililik yeterlik ölçek puanlarını karşılaştırmak için Tek Yönlü Varyans Analizi (ANOVA) kullanılmıştır. Öğrencilerin problem çözme becerileri ile öz etkililik yeterlik puan ortalamaları arasındaki farkın hangi sınıflardan kaynaklandığını belirlemek için Scheffe testi, problem çözme becerileri ve öz etkililik yeterlik düzeyleri arasındaki ilişkiyi belirlemek için Pearson Korelasyon testi uygulanmıştır. Çalışmada yer alan ölçeklerin Cronbach alfa katsayıları hesaplanmıştır. Araştırmada istatistiksel önemlilik düzeyi 0.05 olarak alınmıştır.

\section{BULGULAR}

Çalışmaya katılan öğrencilerin yaş ortalaması 21.13 \pm 2.56 olarak bulunmuştur. Öğrencilerin \%24.8'i üçüncü sınıf, $\% 80.1$ 'inin geliri giderine eşit, \%77.5'i yurtta kalmakta, $\% 40.8$ 'i en uzun süre ilçede yaşamış, \%83.3'ü çekirdek aile yapısına sahip, \%43.1'i iki kardeşe sahip ve \%83.7'si ise ebelik bölümüne isteyerek gelmiştir (Tablo 1).

Tablo 1. Öğrencilerin Demografik Özellikleri (n=306)

Tablo 1. Ögrencilerin Demografik Ozellikleri (n=306)
\begin{tabular}{|c|c|c|}
\hline Demografik özellikler & $\begin{array}{c}\text { Sayı } \\
\text { (n) }\end{array}$ & $\begin{array}{c}\text { Yüzde } \\
\text { (\%) }\end{array}$ \\
\hline Sinıf & & \\
1. sınıf & 84 & 27.5 \\
2. sınıf & 74 & 24.2 \\
3. sınıf & 76 & 24.8 \\
4. sınıf & 72 & 23.5 \\
\hline Gelir durumu & & \\
Gelir giderden az & 61 & 19.9 \\
Gelir gidere eşit & 245 & 80.1 \\
\hline Yaşadıkları yer & & \\
Aile ile birlikte & 33 & 10.8 \\
Arkadaşı ile evde & 36 & 11.7 \\
Yurtta & 237 & 77.5 \\
\hline En uzun süre yaşanılan yer & & \\
Şehir & 118 & 38.6 \\
İlçe & 125 & 40.8 \\
Köy & 63 & 20.6 \\
\hline Aile tipi & & \\
Çekirdek & 255 & 83.3 \\
Geniş & 51 & 16.7 \\
\hline Kardeş sayısı & & \\
Yok & 18 & 5.9 \\
Bir & 121 & 39.5 \\
İki & 132 & 43.1 \\
Üç ve üstü & 35 & 11.5 \\
\hline Bölüme isteyerek gelme durumu & \\
Evet & 50 & 83.7 \\
Hayır & & \\
\hline
\end{tabular}

Çalışmaya katılan öğrencilerin sınıflara göre PÇE puan ortalamaları Tablo 2'de verilmiştir. Bu sonuçlara göre; öğrencilerin sınıf seviyesi arttıkça PÇE puan ortalamalarının azaldığı ve yapılan istatistiksel değerlendirmede bu farkın istatistiksel olarak anlamlı olduğu belirlenmiştir $(\mathrm{p}=0.029)$. Hangi gruplar arasında anlamlı farkın olduğunu ortaya koymak için yapılan Scheffe testi sonucunda, 2. siniflarla 1. siniflar arasindaki farkin $(p=0.002) 2$. sinif lehine, 3. sinifla $2(p=0.003)$ ve 1. $\sin 1 f(p=0.002)$ arasındaki farkın 3. sinıf lehine ve 4 . sinifla $3(p=0.003), 2(p=0.002)$ ve 1 . sinif $(p=0.000)$ arasındaki farkın da 4 . sınıf lehine olduğu tespit edilmiştir.

Tablo 2. Öğrencilerin Sınıflara Göre PÇE Puanlarına Ait Tanımlayıcı İstatistikler ve Karşılaştırma Sonuçları (n=306)

\begin{tabular}{|c|c|c|c|c|}
\hline Sinıf & $\mathbf{n}$ & $\begin{array}{c}\text { PÇE } \\
(\text { Ort } \pm \text { SS) }\end{array}$ & $\mathbf{F}$ & $\mathbf{p}$ \\
\hline 1. Sinif & 84 & $126.14 \pm 15.96$ & \multirow{4}{*}{0.695} & \multirow{4}{*}{0.029} \\
\hline 2. Sinif & 74 & $119.33 \pm 14.45$ & & \\
\hline 3. Sinif & 76 & $113.47 \pm 15.36$ & & \\
\hline 4. Sinıf & 72 & $107.45 \pm 15.21$ & & \\
\hline
\end{tabular}

PÇE: Problem Çözme Envanteri, Ort: Ortalama, SS: Standart Sapma 
Sınıflar arasındaki bu farkın sebebi sınıf seviyesi yükseldikçe ortalama puanın düşmesidir. PÇE'de puan düştükçe problem çözme becerisi artmaktadır.

Tablo 3. Öğrencilerin Sınıflara Göre ÖEYÖ Toplam Puanlarına Ait Tanımlayıcı İstatistikler ve Karşılaştırma Sonuçları $(\mathrm{n}=306)$

\begin{tabular}{|c|c|c|c|c|}
\hline Sınıf & $\mathbf{n}$ & $\begin{array}{c}\text { ÖEYÖ } \\
\text { (Ort } \pm \text { SS) }\end{array}$ & F & p \\
\hline 1. Sinıf & 82 & $90.25 \pm 9.56$ & & \\
\cline { 1 - 2 } 2. Sinıf & 75 & $85.21 \pm 11.58$ & \multirow{2}{*}{2.96} & \multirow{2}{*}{0.844} \\
\cline { 1 - 2 } 3. Sinıf & 73 & $90.01 \pm 11.23$ & & \\
\hline 4. Sinıf & 80 & $87.34 \pm 10.45$ & & \\
\hline
\end{tabular}

ÖEYÖ: Öz Etkililik Yeterlik Ölçeği, Ort: Ortalama, SS: Standart Sapma

Araştırmaya katılan öğrencilerin sınıflara göre ÖEYÖ toplam puan ortalamaları Tablo 3'te verilmiştir. Öğrencilerin sinıflara göre ÖEYÖ toplam puan ortalamalarının birbirine oldukça yakın olduğu ancak aradaki farkın anlamlı olmadığ Tablo 3).

Tablo 4. Öğrencilerin PÇE ve ÖEYÖ Puanlarına Ait Tanımlayıcı İstatistikler ve Karşılaştırma Sonuçları $(\mathrm{n}=306)$

\begin{tabular}{|c|c|c|c|}
\hline $\begin{array}{c}\text { PÇE } \\
\text { (Ort } \pm \text { SS) }\end{array}$ & $\begin{array}{c}\text { ÖEYÖ } \\
\text { (Ort } \pm \text { SS) }\end{array}$ & r & p \\
\hline $116.36 \pm 16.76$ & $88.21 \pm 9.06$ & -0.435 & $<0.001$ \\
\hline
\end{tabular}

PÇE: Problem Çözme Envanteri, ÖEYÖ: Öz Etkililik Yeterlik Ölçeği, Ort: Ortalama, SS: Standart Sapma

Öğrencilerin PÇE ve ÖEYÖ puanları Tablo 4'te verilmiştir. Öğrencilerin problem çözme becerileri ile öz etkililik yeterlik düzeyleri arasında negatif yönde orta şiddette anlamlı ilişki saptanmıştır $(\mathrm{r}=-0.435, \mathrm{p}<0.001)$.

\section{TARTIŞMA VE SONUÇ}

Ebelik öğrencilerinin problem çözme becerileri ile öz etkililik yeterlik düzeyleri arasındaki ilişkiyi belirlemek amacıyla analitik ve kesitsel olarak yapılan bu çalışmada, öğrencilerin problem çözme becerileri ile öz etkililik yeterlik düzeyleri arasında negatif yönde orta şiddette ilişki olduğu, sınıflara göre problem çözme beceri puanları bakımından anlamlı fark bulunurken, öz etkililik yeterlik düzeyleri açısından ilişki bulunmadığ sonuçlarına ulaşılmıştır. $\mathrm{Bu}$ sonuçlar, ebelik eğitiminin öğrencilerin öz etkililik yeterlik düzeyleri üzerinde etkili olmadığını ve öğrencilerin öz etkililik yeterlik düzeylerinin arttırılması ile problem çözme becerilerinin de arttırılabileceğini göstermesi bakımından önemlidir.

Araştırmada öğrencilerin sınıf seviyesi arttıkça PÇE puan ortalamalarının azaldığı ve yapılan istatistiksel değerlendirmede bu farkın önemli olduğu belirlenmiştir. $\mathrm{Bu}$ sonuç yapılan diğer çalışma sonuçlarını desteklemektedir (2,17-19). Ayrıca sağlık bilimlerinde eğitim alan doktora öğrencileri ile yapılan bir çalışmada öğrencilerin problem çözme becerilerinin lisans öğrencilerine göre oldukça iyi olduğu saptanmıştır (20). $\mathrm{Bu}$ sonuçlar öğrencilerin eğitimle birlikte problem çözme becerilerinin de arttığını göstermesi bakımından önemlidir.
Araştırmaya katılan öğrencilerin ÖEYÖ puan ortalamalarının sınıflara göre anlamlı fark göstermediği ve bu sonucun literatürde yapılmış çeşitli çalışmalar $(21,22)$ ile benzerlik gösterdiği görülmüştür. $\mathrm{Bu}$ sonuç; öğrencilerin öz etkililik yeterlik düzeyleri üzerinde ebelik eğitiminin etkili olmadığını düşündürmektedir.

Araştırmada öğrencilerin problem çözme becerileri ile öz etkililik yeterlik düzeyleri arasında negatif yönde orta şiddette anlamlı ilişki saptanmıştır. Bu sonuç öğrencilerin öz etkililik yeterlik düzeylerinin arttırılması ile problem çözme becerilerinin de arttırılabileceğini göstermektedir. Ancak yapılan literatür taramasında ülkemizde ebelik öğrencileri ile yapılmış problem çözme becerileri ile öz etkililik yeterlik düzeylerinin karşılaştırıldığı herhangi bir çalışmaya rastlanmamıştır. Dolayısıyla tüm bu sonuçlar, ebelik öğrencilerinin problem çözme becerileri ile öz etkililik yeterlik düzeylerinin karşılaştırıldığı farklı çalışmalara ihtiyaç olduğunu düşündürmektedir. Ayrıca ebelik eğitim müfredatına problem çözme becerilerinin geliştirilmesine katkı sağlayacak seçmeli derslerin eklenmesi önerilebilir.

\section{KAYNAKLAR}

1. Yörük S. Dünya'da ebelik eğitimi. Düzce Üniversitesi Sağlık Bilimleri Enstitüsü Dergisi. 2016; 6(1): 46-50.

2. Şen E, Amanak K, Akgün E, Karagöz D. Ebelik öğrencilerinin kontrol odağ1 ve problem çözme beceri düzeyleri arasındaki ilişki. Balıkesir Sağlık Bilimleri Dergisi. 2014; 3(2): 94-101.

3. Dikmen Y, Denat Y, Başaran H, Filiz NY. Hemşirelik öğrencilerinin öz etkililik-yeterlik düzeylerinin incelenmesi. Journal of Contemporary Medicine. 2016; 6(3): 206-13.

4. Çetinkaya A, Özmen D, Fadıloğulu Ç. Geleceğin sağlı profesyonellerinin öz-etkililik-yeterlik düzeyleri ile sosyal destek algıları arasındaki ilişki. Gümüşhane Üniversitesi Sağlık Bilimleri Dergisi. 2014; 3(4): 1045-55.

5. Karadağ E, Derya AY, Ucuzal M. Sağlık yüksekokulu öğrencilerinin öz etkililik-yeterlik düzeyleri. Maltepe Üniversitesi Hemşirelik Bilim ve Sanatı Dergisi. 2011; 4(1): 13-20.

6. Keskin ÜG, Orgun F. Öğrencilerin öz etkililikyeterlilik düzeyleri ile başa çıkma stratejilerinin incelenmesi. Anadolu Psikiyatri Dergisi. 2006; 7(2): 92-9.

7. Britner SL. Motivation in high school science students: A comparison of gender differences in life, physical, and earth science classes. JRST. 2008; 45(8): 955-70.

8. Bray C, Nash K, Robin D, Froman R. Validation of measures of middle schoolers' self-efficacy for physical and emotional health, and academic tasks. RINAH. 2003; 26(1): 376-86.

9. Arabacı İB, Namlı A, Zincirli M, Özer F. Eğitim kurumlarının stratejik plan geliştirme ve uygulama sürecinde karşılaştıkları sorunlar ve çözüm önerileri. K. Ü. Kastamonu Eğitim Dergisi. 2015; 23(4):145370.

10. Kartal Ay, Yazıcı S. Ebelik öğrencilerinin ilk klinik deneyim başlangıcı ve sonunda anksiyete ve stres düzeylerinin belirlenmesi. Sağlık Bilimleri ve Meslekleri Dergisi. 2017; 4(3): 190-5. 
11. Heppner P, Petersen CH. The development and implications of a personal problem-solving inventory. Journal of Counseling Psychology. 1982; 29(1): 6675.

12. Savaşır I, Şahin NH. Bilişsel-davranışçı terapilerde değerlendirme: Sık kullanılan ölçekler. Türk Psikologlar Derneği Yayınları. Ankara: Özyurt Matbaacilık; 1997.

13. Şahin N, Şahin NH, Heppner PP. Psychometric Proporties of the Problem Solving Inventory in a Group of Turkish University Students. Cognitive Therapy and Research. 1993; 4(17): 379-96.

14. Dağ İ. Belirti tarama listesi (SCL-90-R)'nin üniversite öğrencileri için güvenirliği ve geçerliği. Türk Psikiyatri Dergisi. 1991; 2(1): 5-12.

15. Sherer M, Maddux JE, Mercandante B, Prentice-Dunn S, Jacobs B, Rogers RW. The Self-Efficacy Scale: Construction and validation. Psychological Reports. 1982; 51(1): 663-71.

16. Gözüm S, Aksayan S. Öz etkililik-yeterlik ölçeğinin Türkçe formunun güvenilirlik ve geçerliliği. Atatürk Üniversitesi Hemşirelik Yüksekokulu Dergisi. 1999; 2(1): 21-34.

17. Durmaz Ş, Kaçar Z, Can S, Koca R, Yeşilova D, Tortumluoğlu G. Çanakkale sağlık yüksekokulu öğrencilerinin problem çözme becerileri (PÇB) ve etkileyen bazı faktörler. Atatürk Üniversitesi Hemşirelik Yüksekokulu Dergisi. 2007; 10(4): 63-71.

18. Yılmaz E, Karaca F, Yılmaz E. Sağlik yüksekokulu öğrencilerinin problem çözme becerilerinin bazı değişkenler açısından incelenmesi. Atatürk Üniversitesi Hemşirelik Yüksekokulu Dergisi. 2009; 12(1): 38-48.

19. Kantek F, Gezer N. Bir sağlık yüksekokulunda öğrencilerin eleştirel düşünme ve problem çözme becerilerinin incelenmesi. 10. Uluslararası Eğitimde Yeni Yönelimler Kongresi; 11-13 Kasım 2010; Antalya. s. 186-90.

20. Cengiz B, Çal A, Açıl D, Bahar Z, Beşer A. Sağlık Bilimlerinde Eğitim Alan Doktora Öğrencilerinin Problem Çözme Becerileri. ACU Sağlık Bil Derg. 2018; https://doi.org/10.31067/0.2018.77.

21. Zengin N. Sağlık yüksekokulu öğrencilerinde özetkililik-yeterlilik algısı ve klinik uygulamada yaşanılan stresle ilişkisinin incelenmesi. Atatürk Üniversitesi Hemşirelik Yüksekokulu Dergisi. 2007; 10(1): 49-57.

22. Yiğitbaş Ç, Yetkin A. Sağlık yüksekokulu öğrencilerinin öz-etkililik-yeterlik düzeyinin değerlendirilmesi. C.Ü. Hemşirelik Yüksek Okulu Dergisi. 2003; 7(1): 6-13. 